\title{
MICROPOLÍTICA DO MEDO E DISPOSITIVOS ESTÉTICOS: ATRAVESSAMENTOS ENTRE ARTE E POLÍTICA PARA OUTROS EFEITOS DE SUBJETIVAÇÃO
}

\author{
Alyne Alvarez SILVA ${ }^{1}$ \\ Maria Cristina Gonçalves VICENTIN ${ }^{2}$
}

\section{Resumo}

Estamos em tempos sombrios, em que as persistentes situações de violação de direitos, de violência de Estado se ancoram na produção de um regime afetivo de envenenamento da socialidade e de produção de práticas autoritárias e intolerantes. Tal regime encontra na difusão do medo e na demanda por segurança um dos seus motores centrais e na prática divisória normal-anormal uma de suas principais modulações. Animalizados ou objetificados, os corpos anormais, "quase desumanos" são alvos das lógicas de poder de controle e punição visando sua transformação ou neutralização, dentre eles a figura paradigmática do louco infrator. A desnaturalização da produção do medo engaja dimensões macro e micropolíticas que alterem o regime de afetabilidade. Neste artigo, situamos o medo como estratégia de governamentalidade, contextualizando sua produção histórica e seus usos para a gestão dos corpos na contemporaneidade, tendo como interlocutores principalmente os aportes de Michel Foucault e de uma criminologia crítica. Apresentamos, em seguida, com base em Rancière e Guattari a arte em sua disposição de transformação do pensamento em experiência sensível da comunidade e os dispositivos estéticos como vetores de dessegregação e abertura à alteridade. Concluímos apontando elementos avaliativos de uma pesquisa-intervenção realizada em manicômio judiciário que pôs em ação diferentes dispositivos estéticos de desinstitucionalização, efetuando a recomposição das corporeidades e afetações: oficinas de arte, exposição itinerante e produção de um filme-documentário buscaram embaralhar os códigos das racionalidades que constituem a medida de segurança, questionando seus sentidos mais naturalizados e abrindo espaço para o desenho de projetos e ações de cuidado.

Palavras-chave: Medo, Governamentalidade, Arte, Dispositivos Estéticos de Desinstitucionalização, Louco infrator

Micropolitics of fear and aesthetic devices: intersections between art and politics for other subjectification effects

\begin{abstract}
We live in dark times, where persistent situations of rights violations and violence by the State are anchored by the production of an affective regime that leads to a poisoning of sociality and the development of authoritarian and intolerant practices. The key drivers behind this regime are the diffusion of fear and a demand for safety, and its main regulator is the normal-abnormal divisory practice. Animalized or objectified, abnormal bodies, "almost inhuman", are targets for power logics of control and punishment that aim at transformation or neutralization; these include the paradigmatic figure of the criminally insane. By making the production of fear unnatural, micro and macropolitical dimensions are involved, altering the affectability regime. In this article, we situate fear as a governmentality strategy, contextualizing its historical production and its uses in contemporary management of bodies, with the main input in the debate coming from Michel Foucault and critical criminology. Next, based on Rancière and Guattari, we discuss art and its ability to transform thought into a sensitive community experience,
\end{abstract}

\footnotetext{
${ }^{1}$ Doutora em Psicologia Social pela Pontifícia Universidade Católica (PUC-SP) e Mestre em Psicologia pela Universidade Federal do Pará (UFPA). Docente do curso de Psicologia na Universidade Federal de Campina Grande (UFPB). Coordenadora do Núcleo de Pesquisa e Extensão sobre Drogas (NUD-UFCG). E-mail: alvarezalyne@gmail.com

${ }^{2}$ Doutora em Psicologia Clínica e Mestre em Psicologia Social pela Pontifícia Universidade Católica (PUC-SP). Docente do Programa de Estudos em Psicologia Social da PUC-SP, onde coordena o Núcleo de Estudos e Pesquisas Lógicas Institucionais e Coletivas. E-mail: cristinavicentin@gmail.com
} 
as well as aesthetic mechanisms such as desegregation vectors and opening up to otherness. Our conclusion highlights the evaluation elements of an intervention survey carried out at a forensic hospital that put in place a number of aesthetic deinstitutionalization mechanisms, restoring corporealities and affectations: art workshops, an itinerant exhibition, and the production of a documentary all sought to scramble the rationality codes that make up security measures, questioning their more natural senses and creating space to design care projects and actions.

Key words: Fear, Governmentality, Art, Aesthetic Deinstitutionalization Mechanisms, Criminally Insane

\section{INTRODUÇÃ̃O}

Estamos vivendo em tempos sombrios, em que se somam às já persistentes situações de violação de direitos e de violência de Estado, que encontramos em nosso país, o desmonte,em curso desde o golpe de $2016^{3}$, de recentes conquistas de direitos sociais.

Ao lado das tensões do debate ideológico em pauta hoje(e das posições ultraconservadoras que têm tido lugar aí) ressaltamos a preocupante produção de um regime afetivo de envenenamento da socialidade, de um regime de ódio que tem regido as reações de muitos diante de situações de conflito ou de frustração e que tem se difundido nos microfascismos da vida cotidiana, na forma de práticas autoritárias e intolerantes.Tal tipo de poder vigente visa a nos separar de nossa força, a nos inculcar a tristeza, a sensação de impotência e, sobretudo, o medo.A difusão do medo tem sido, na formação social brasileira um mecanismo central de gestão "indutor de tomadas de posição estratégicas seja no campo econômico, político ou social" (BATISTA, 2003, p. 23).

No regime dos medos, a modernidade constituiu o "anormal" como uma de suas formas principais. Os "anormais", os não normalizáveis ou que se insubordinam ou subvertem as normas, para o "bem" o para o "mal", são postos como a ameaça constante ao utópico e fantástico mundo sem violência para o qual uma parafernália de aparatos violentos é constantemente usada e atualizada.

Aos que desviam dos modos de ser facilmente governáveis e desordenam o campo político existente são impostas medidas de controle, contenção, coerção, objetivando, no mínimo, sua transformação e/ou neutralização. Tais medidas são impostas aos que não alimentam a cadeia produtiva a contento; aos que se esquivam do governo da individualização

\footnotetext{
${ }^{3}$ Trata-se da destituição arbitrária da então presidente Dilma Roussef,em 2016, sob o pretexto de irregularidades contábeis para cobrir déficits nas contas públicas. Desde então, vemos o congelamento de gastos sociais e propostas de reformas estruturais que visam a "mercadorização" da educação, da saúde e da Previdência.
} 
(FOUCAULT, 1995); aos que oferecem resistência aos assujeitamentos cotidianos que os tornaria "normais", isto é, dóceis economicamente e úteis politicamente, como nos ensina Foucault (2010); aos que são alvo da criminalização de seus questionamentos à ordem, de suas dissidências (FOUCAULT, 2010).

A estes são previstos os processos de institucionalização com efeitos de aniquilamento ou mortificação subjetiva (GOFFMAN, 2001), já que, quando se trata mais especificamente de modalidades de uma governamentalidadebiopolítica ${ }^{4}$, sempre haverá aqueles que deverão morrer em favor da vida de outros, em forma de racismo de estado (FOUCAULT, 2005). Animalizados ou objetificados, estes corpos resumidos a um corpo biológico, quase desumano, escapam do escopo dos direitos humanos, muitas vezes tornando insensíveis aqueles que são considerados merecedores da vida e da vida em liberdade.

A matriz de construção dessa humanidade, dessas práticas de controle social e de esmagamento das vidas ditas desviantes, pauta-se no entendimento do mundo ordenado por verdades universais inquestionáveis, por vezes, tidas como transcendentais, o que sugere o certo e o errado e tantas outras divisões binárias que guiam o olhar e o entendimento sobre o mundo, quase sempre maniqueístas e moralistas, apartados do contexto de produção dos acontecimentos. Esse entendimento amparado e propagado por saberes intitulados de científicos, que defendem o mesmo regime de poder, é extremamente útil à busca incessante da manutenção das relações de poder já instituídas, não admitindo surpresas no curso de seu funcionamento e, portanto, evitando ou abafando, a todo custo, os conflitos, as divergências, as desordens, contradições e paradoxos que constituem a existência humana.

Encontra-se aí a compreensão da vida regida por identidades que seriam definidas por regimes de pessoalidades ${ }^{5}$ (ROSE, 2001) que variam sempre entre dois extremos: normal e anormal, louco e são, delinquentes e não delinquentes, virtuosos e não virtuosos, portanto, bipolarizando e hierarquizando seus componentes, tendendo a esterelizá-los.Os sistemas punitivos

\footnotetext{
${ }^{4}$ Trata-se, segundo Foucault $(2005 ; 2010)$, das práticas contínuas de regulação, correção, qualificação, medição, avaliação e hierarquização da vida, na forma das tecnologias disciplinares que visam a gestão do espaço e do tempo (vigilância, sanção normalizadora, exame) de forma a ampliar a docilidade e a utilidade dos indivíduos necessários ao modo capitalista de produção, assim como as ações de regulamentação e regulação, que tomam a população como objeto privilegiado de governo para zelar por seu bem-estar e em defesa da vida (os nascimentos, as doenças e as mortes constituem exemplos desses processos).

${ }^{5}$ Os "regimes de pessoalidade", segundo Rose (2001), são esquemas mais ou menos racionalizados bem inventados para ocupar o ser humano da busca incessante de seu lugar no mundo, sendo este lugar enquadrado em conceitos pré-formatados acerca de si, como, por exemplo, os conceitos de cidadão, masculinidade, feminilidade, mãe, honra, generosidade, etc. Neste caso, o conceito de homem trabalhador e disciplinado.
} 
e de controle social têm, a partir dessa linha divisória (FOUCAULT, 1995), alvos fáceis contra os quais agir e neutralizar com o fim de evitar o caos no mundo supostamente ordenado.

As torturas, a violência de estado, os genocídios da juventude negra e pobre, as prisões, os hospitais psiquiátricos, os manicômios judiciários, suas derivações e simulacros, bem como os saberes que os sustentam como práticas legítimas e resolutivas, fazem-se amparados nessa perspectiva. São, por excelência, os aparatos para se lidar com todo tipo de desordem, imprevisibilidades e ameaças a esse regime. Afirmam e reafirmam cotidianamente a necessidade de afastar do convívio os incapazes de se manterem submissos à ordem, colocando em questão a suposta natural ordenação e paz do mundo.

O estranho, o sujo, a desordem e/ou o caos não provocam medo naturalmente. Foram forjados e construídos socialmente ao longo da história da humanidade e precisariam ter seus contextos de produção resgatados para que fossem minimamente desnaturalizados (Cf. CALDEIRA, 1991，2000; COIMBRA， 1998; BATISTA, 2003; ZAFFARONI, 2007; WACQUANT, 2007; RAUTER, 2014). A análise dos acontecimentos que os instituíram tornarse-ia importante na medida em que fomos constituídos subjetivamente ao longo da história como sujeitos medrosos capazes não apenas de legitimar práticas violentas de controle social, como aplaudir ações ilegais contra tudo aquilo que pareça ser fonte dos medos, em nome da segurança.

Estes agenciamentos configuram muitas vezes um campo de organização molar (DELEUZE e GUATTAR,1996), quando o plano intensivo da vida é constrangido em formas de subjetivação assentadas em verdades julgadas como essenciais, parte da natureza de cada indivíduo e, portanto, não passíveis de questionamento e mudança. Mas como há também um acontecer micropolíticoda política, que engaja indeterminações e devires (Idem), há uma margem de deslocamentos e desmanchamentos que aqui tratamos sob a perspectiva da desinstitucionalização. Tal modo de intervenção supõe a constituição de diferentes dispositivos, dentre estes os estéticos, e que foram experimentados no âmbito de uma proposta de pesquisa-intervenção como estratégia de desinstitucionalização do medo de uma das figuras paradigmáticas na histórica construção dos meios de governo dos corpos, o louco infrator.

Neste artigo, pretendemos situar o medo como estratégia de governamentalidade, partindo de uma breve contextualização de sua produção e dos seus usos para a gestão dos corpos na contemporaneidade, bem como apontando seus efeitos de subjetivação. Em contraposição, apresentamos algumas considerações sobre a arte em sua disposição para a 
construção do comum e os dispositivos estéticos como vetores de dessegregação e abertura à alteridade. Apostando na força disruptiva da arte, finalizamos, apontando alguns dispositivos estéticos,forjados no decorrer da pesquisa que deu base a este artigo (SILVA, 2015), utilizados como estratégia de desnaturalização do medo e, consequentemente, para a desinstitucionalizaçãode pessoas com transtornos mentais que entram em conflito com a leie cumprem medida de segurança encerradas nos intoleráveis manicômios judiciários ${ }^{6}$.

\section{A PRODUÇÃO DO MEDO COMO ESTRATÉGIA DE GOVERNAMENTALIDADE}

(...) raramente as pessoas têm a coragem de admitir simplesmente que tem medo, recorrendo a argumentos lógicos sofisticados para desqualificar e combater aquilo que é visceralmente temido. O medo esse móvel amargo e inconfessável dos sujeitos históricos, pode ser tão elucidativo em alguns momentos, ou até longos períodos, quanto o estudo da acumulação de capital (CHALOUB apud BATISTA, 2003, p. 37).

Vera Malaguti Batista (2003), em "O medo na cidade do Rio de Janeiro" analisa o imaginário do medo em sua relação com o caráter autoritário das estratégias de controle social no Brasil. Sua hipótese é a de que "a hegemonia conservadora na nossa formação social trabalha a difusão do medo como mecanismo indutor de tomadas de posição estratégicas seja no campo econômico, político ou social” (p. 23).

Segundo Neder (apud BATISTA, 2003), em nossa formação socioeconômica, as fantasias de controle social e policial absoluto têm como matriz a cultura jurídico-política da Península Ibérica. Imagens de morte e terror nos acompanham desde a colonização, não apenas por seus efeitos genocidas, de escravização e sujeição dos povos ditos primitivos, mas também pela cultura inquisitorial ibérica que fantasiava exercer um absoluto controle social sobre qualquer ameaça à sua hegemonia política.

Para Zaffaroni (2007), o poder punitivo, como instrumento de controle e verticalização social, impôs-se perversamente desde sua origem por meio de preconceitos que impunham medo. A perseguição às bruxas, no modelo inquisitorial, foi seguida por tribunais laicos e, depois, generalizou-se. "Na Espanha, os principais inimigos nunca foram as bruxas embora muitas tenham sido eliminadas -, mas sim os opositores do monarca, acusados de

\footnotetext{
${ }^{6}$ Nomeados, em 1984, pela Lei de Execução Penal (BRASIL, 1984) de Hospitais de Custódia e Tratamento Psiquiátrico/HCTP.
} 
hereges e dissidentes, isto é,hostis judicatus, prolongando-se a Inquisição até o século XIX” (p. 34).

Dado que os povos nativos eram considerados biologicamente inferiores, o poder punitivo transformou as sociedades colonizadasem imensos campos de concentração. Dentre os povos mestiços e nativos, impôs-se uma separação que desestimulava a mestiçagem, já que os primeiros eram considerados menos domesticáveis. O discurso penal tratou de considerálos desequilibrados ou loucos morais em potencial; consequentemente, inimputáveis para, então, conseguir exercer sobre eles maior controle e exclusão, quando "convertiam os mais rebeldes em inimigos" (ZAFFARONI, 2007, p. 47).

Jean Delumeau (apud BATISTA, 2003), historicizando o medo, divide-o em dois grandes blocos: de um lado, os medos da maioria, relacionados à Peste e aos flagelos tradicionais, como a fome e as guerras; e de outro, o medo da cultura dirigente de perder sua hegemonia política. A relação entre eles está no fato de que os medos da maioria, com o consequente medo da morte, serviram e muito bem para atender à cultura dirigente, já que atuaram como importantes elementos na construção de instrumentos de ordenação e limpeza do espaço:

O medo explica a ação persecutória conduzida pelo poder político-religioso. As fórmulas de confinamento 'saneiam as cidades', diminuem os 'perigos de contágio', têm alcance moral. O sentido maior desta estratégia é disciplinar populações, produzindo alinhamentos (BATISTA, 2003, p. 45).

Batista (2012) soma,aos efeitos dessa história, o atual contexto neoliberal - analisado a partir das obras de LöicWacquant - na produção de uma subjetividade contemporânea predominantemente punitiva. O desejo de punir cada vez mais encrustado na população corresponderia ao excesso de insegurança social provocado, de modo sintético, pelas características mais centrais do neoliberalismo, quais sejam: a (1) desregulação do mercado com consequente (2) esfacelamento do trabalho, somados à (3) ênfase na responsabilidade individual e na (4) ampliação das estruturas penais.

Há uma série de mudanças culturais, apontadas por Wacquant (2007, p. 28) como promotoras de "sentimentos de insegurança" - "crise da família patriarcal e erosão das tradicionais relações de autoridade entre os sexos e as faixas etárias, decomposição dos territórios da classe trabalhadora, generalização da competição escolar" - que geralmente são confundidas com insegurança social e acabam canalizando à figura do delinquente as 
ansiedades difusas provocadas pelo que é mais central no neoliberalismo. Para o autor, a fonte de insegurança social estaria nos efeitos da precarização do trabalho, antes assalariado e estável, e a consequente vulnerabilização de parcelas da população que, com baixa qualificação profissional e menor capital cultural, escoam para o trabalho informal ou para o desemprego e tornam-se alvo das políticas de segurança pública. Estas serão incumbidas de fazer um rígido controle social, apoiadas no fortalecimento do sistema penal, em franca expansão de suas estruturas punitivas, em contraposição ao recuo das políticas de assistência social que deveriam sanear a insegurança sofrida pela população pobre ou empobrecida.

Seria o avanço do Estado Penal em sincronia com os recuos do que seria função do Estado de bem-estar social, dentro do que Wacquant (2007, p. 30) descreve como tríplice transformação do Estado: aliança da "amputação do seu braço econômico à retração de seu regaço social e à maciça expansão do seu punho penal". O autor afirma que o neoliberalismo transformou a assistência social em prática de tratamento penal da marginalidade urbana e demonstra que os EUA impuseram um "novo governo da insegurança social" não apenas pelo deslocamento dos gastos públicos do social para o penal, mas também pelo manejo da população a partir da área assistencial através da "lógica punitiva e panóptica" (Ibidem, p. 04).

Em trabalho anterior, o autor exemplifica essa nova governamentalidade com a globalização da política de Tolerância Zero e o consequente encarceramento em massa, iniciados na década de 1970 nos EUA, sociedade que, fortalecida após o 11 de setembro de 2011, sinalizou ao mundo a instauração de um Estado Penal (WACQUANT, 2001), concomitante à do Estado Democrático de Direito, com práticas que influenciam fortemente os países da América Latina. Com efeito, no Brasil, nos anos 1990 e 2000, assistimos a um aumento vertiginoso da população carcerária. Segundo os dados do DEPEN (Departamento Penitenciário Nacional), em 1990, havia no sistema penitenciário 90 mil presos; em 2012, esse número chega a quase 550 mil, o que significa um aumento de $511 \%$ da população carcerária no país. Hoje, passamos dos 700 mil apenados, o que coloca o país em terceiro lugar no ranking dos países que mais encarceram no mundo, ficando atrás apenas dos EUA e da China (VERDÉLIO, 2017).

Para Wacquant, desenvolver o Estado penal é restabelecer uma verdadeira "ditadura sobre os pobres", já que o mesmo funciona para: 
responder às desordens suscitadas pela desregulamentação da economia, pela dessocialização do trabalho assalariado e pela pauperização relativa e absoluta de amplos contingentes do proletariado urbano, aumentando os meios, a amplitude e a intensidade da intervenção do aparelho policial e judiciário (WACQUANT, 2001, p. 10).

Nesse sentido, não apenas se autoriza o uso da violência estatal como se permitem práticas extremas de arbitrariedade, sem que ninguém se escandalize - como era de se esperar - a exemplo dos métodos de tortura como formas de investigação - desde que direcionadas aos setores da sociedade identificados como suspeitos ou perigosos. Como diz Kolker (2002, p. 93), "quando pensávamos que as democracias modernas teriam mais instrumentos para coibir a violência estatal, verificamos que a tortura coexiste muito bem com a ordem constitucional".

Considerando a realidade brasileira, parece mais fácil entender as análises de Wacquant quando as relacionamos ao período da ditadura civil-militar, já que o estabelecimento da Doutrina de Segurança Nacional, em que a segurança do país se volta às ameaças provocadas por "inimigos internos", justifica o explícito sacrifício do que viria a ser função de um Estado de bem-estar social com "a limitação das liberdades, das garantias constitucionais, dos direitos da pessoa humana" (COIMBRA, 1998, p. 09). Os dispositivos do Sistema Internacional de Segurança, que deveriam servir para a garantia da soberania do país, tornam-se a base do Sistema de Segurança Nacional, em que as táticas de guerra passam a ser utilizadas contra a própria população com vistas a garantir a ordem. É o que se vê nas frequentes cenas de guerra que vivem as camadas populares: enfrentando balas mortais, toques de recolher, invasões domiciliares sem mandado de segurança, desaparecimentos, mortes registradas, até 2013, como Resistência Seguida de Morte/RSM, expressão substituída por "homicídios decorrentes de intervenção policial" (RAUTER, 2014), dentre outras violações. A demora para a abertura dos arquivos da ditadura para a devida responsabilização dos mandantes dos crimes que ensejou - modo de o Estado brasileiro assumir posição explícita contra práticas de tortura, deslegitimando sua continuidade em outros contextos atualizam a violência estatal e a figura do inimigo interno, a exemplo das cenas corriqueiras de ataques brutais das polícias contra a população, legitimados pelo Estado.

Em consonância às análises de Wacquant, Cecília Coimbra empresta a expressão "paradigma da insegurança" de Pegoraro (apud COIMBRA, 2001) para descrever o fenômeno que se instaura no Brasil, já na década de 1980, anunciando o cenário das décadas seguintes, a 
partir de pelo menos duas questões: de um lado uma forte campanha das grandes mídias associando o fim da ditadura civil-militar ao aumento da criminalidade, colocando em voga discursos e práticas sobre a violência e perigos contra os quais a população deveria se proteger, aceitando um policiamento ostensivo e sendo incitadas a linchamentos, autoarmamento, etc. Em tempos de recessão econômica, resultante dos governos ditatoriais, a criminalidade passa a ser a principal bandeira de políticos bastante interessados em tirar do foco os efeitos altamente negativos da recessão sobre o corpo social. Por outro lado, uma nova ordem mundial acabava de se impor: Estado mínimo, livre comércio, privatizações, competitividade, discursos sobre eficiência e responsabilidade individual etc., caracterizam o neoliberalismo e seus efeitos como o próprio "paradigma da insegurança" na medida em que as constantes ameaças de desestabilização econômica e a incipiente catástrofe social - devido ao desemprego e à pobreza, resultantes desta governamentalidade - propagam o medo e a insegurança entre as pessoas das classes médias e das classes trabalhadores e, consequentemente, promovem mais violência urbana e violência estatal, com ampliação das ações penais.

O medo e a insegurança produzidos por estes projetos neoliberais, sem dúvida, têm gerado mais violência. O colapso dos serviços públicos em geral com a implantação do chamado "Estado Mínimo" produz cada vez mais insegurança e desassistidos (COIMBRA, 2001, p. 146).

Nessa mesma direção, Matsumoto (2013) entende a potencialização das ações e políticas penais - com encarceramento em massa da população expropriada - em complementação às políticas sociais compensatórias, as quais seriam expressões que caracterizam as contradições da atual crise do capital. As populações pobres e marginalizadas, como resultado do governo neoliberal, seriam os inimigos aos quais se destinam modos de neutralização para evitar maiores desestabilizações diante de tal crise. A autora forja em sua tese o que chama de "Estado Democrático de Direito Penal" como uma categoria de análise que:

encerra em si esta contradição do Estado Burguês em que convive a igualdade jurídico-política com a faceta de classe do Estado, qual seja, totalitária, penal e policial para os trabalhadores e, principalmente, para aqueles em situação de subemprego ou desemprego (MATSUMOTO, 2013, p. 19).

Ao problematizar a crise estrutural de acumulação do capital, que tem caracterizado o sistema capitalista desde a década de 1960, com consequência de precarização do trabalho e produção destrutiva, a autora afirma que há clara disjunção em termos de "produção para as 
necessidades sociais e autorreprodução do capital" (ANTUNES apud MATSUMOTO, 2013, p. 29).

Caldeira (2000), em pesquisa que relaciona criminalidade, democracia e espaço urbano, apresenta a tese de que a transição democrática ocorrida no Brasil configurou a nossa sociedade como uma "democracia disjuntiva", em que a expansão da cidadania política desenvolveu-se paralelamente a uma deslegitimação da cidadania civil. A privatização do espaço urbano e os mecanismos de segurança policial são dois aspectos que ilustram a "democracia disjuntiva" da qual nos fala a autora, pois determinam o modo de circulação na cidade num jogo de inclusão e exclusão. Segundo a autora:

\begin{abstract}
No contexto da transição para a democracia, o medo do crime e os desejos de vingança privada e violenta vieram simbolizar a resistência à expansão da democracia para novas dimensões da cultura brasileira, das relações sociais e da vida cotidiana (CALDEIRA, 2000, p. 375).
\end{abstract}

Com a privatização do espaço público e dos meios de prevenção da violência, com investimentos maciços em segurança privada - e mais atualmente, clamor geral por segurança pública - e com discursos de legitimação da violência estatal contra as camadas empobrecidas, a parcela abastada da população passa a impor uma distância social, que deveria ter função de gerar sensação de segurança numa relação de diferenciação, separação e exclusão, de total incompatibilidade com a garantia dos direitos das classes populares.

A privatização como solução não só para o problema da criminalidade, mas também para o da expansão do espaço público e dos direitos coletivos das camadas dominadas, elabora-se numa lógica que é exatamente oposta à da expansão dos direitos. Enquanto estes afirmam o que é comum a todos, a igualdade dos cidadãos e os direitos que seriam do conjunto dos membros da sociedade, a privatização enfatiza diferença, privilégio, distinção (CALDEIRA, 1991, p. 173).

Na interseção entre violência e democracia, entre Estado Penal e Estado de direito, um dos grandes desafios para o estabelecimento deste último seria, por exemplo, trazer as forças policiais para dentro dos seus parâmetros, já que os elevados índices de uso da força letal e abuso de autoridade dirigidos, principalmente, a pessoas tidas como suspeitas ou presas demonstram amplo desrespeito das forças policiais aos direitos humanos (CALDEIRA, 2002). Para a autora, a dificuldade de consolidação de uma sociedade democrática não disjuntiva no Brasil reside na consideração dos direitos humanos e direitos individuais como privilégios de alguns em detrimento de outros, o que implica na legitimação da violência e a arbitrariedade contra estes "outros" dos quais querem sempre se diferenciar. 
Rauter (2014) também afirma que vivemos numa democracia para poucos: a proclamação da República com a tardia abolição da escravidão não permitiu aos ex-escravos serem considerados cidadãos, os quais continuam sendo vistos como perigosos, pessoas que não identificamos como semelhantes e, por isso, perdura o cenário de morte ${ }^{7}$ dessa população no país, sem grandes ações coletivas que busquem mudar esse quadro. Inspirada em Spinoza, a autora afirma que:

É também a partir dos afetos que nos contagiamos pelos afetos daqueles que consideramos nossos semelhantes, chegando a constituir um corpo comum com eles, numa linha horizontal. (...). Os habitantes das cidades brasileiras costumam não considerar como semelhante o jovem, negro e pobre, que é geralmente visto como suspeito de crime, e por essa razão não têm afetos de comiseração por suas mortes. Esse e outros fatores comprometem a capacidade de estabelecer laços afetivos horizontais que permitam a um povo se revoltar, construindo saídas coletivas. A produção (...) de nossos afetos, faz parte das artes de governar e nossa contemporaneidade construiu para isso tecnologias complexas (RAUTER, 2014, p. 08).

Considerando a coexistênciaentre o Estado penal e o Estado Democrático de Direito, com as devidas particularidades do Brasil e países da América Latina, importa dizer do efeito do neoliberalismo como "potente motor cultural" na direção do que Vera Malaguti Batista (2012) chamou de "adesão subjetiva à barbárie". Isto é, a inculcação subjetiva do desejo de punir, subjetividade imposta pela cultura punitiva em virtude do medo. Medo como consequência deplorável da radicalização da ordem econômica.

A adesão subjetiva à barbárie seria efeito de uma sociedade fascinada e, ao mesmo tempo, aterrorizada pelo excesso de violência veiculada pelas mass media, que não cansam de isentar os governos liberais de suas responsabilidades sociais e políticas quando apontam incessantemente a criminalidade, ou melhor, os criminosos (preferencialmente de pele preta e com status de pobre), como modo de individualizar a causa de todos os males contemporâneos, sem fazer qualquer relação com os efeitos próprios do neoliberalismo.De acordo com Wacquant (2007, p. 29):

\begin{abstract}
Não foi tanto a criminalidade que mudou no momento atual, mas sim o olhar que a sociedade dirige a certas perturbações da via pública, isto é, em última instância, para as populações despossuídas e desonradas (pelo seu estatuto ou por sua origem) que são seus supostos executores, para o local que elas ocupam na cidade e para os usos aos quais essas populações podem ser submetidas nos campos políticos e jornalísticos.
\end{abstract}

\footnotetext{
${ }^{7}$ Entre 1980 e 2010, houve um crescimento 33,4\% do número de jovens mortos. Em 2010, foram assassinados $132 \%$ mais negros do que brancos. Em 2002,foram 65\% mais negros do que brancos (RAUTER, 2014). 
A produção imagética do terror cumpre, até hoje, papel disciplinador ancorado nessas matrizes constitutivas, produzindo fantasias de pânico do "caos social" quando da ocupação dos espaços públicos pelas classes populares, como citamos anteriormente. Daí a criminalização dos movimentos e das manifestações sociais e o uso do poder de polícia como violência de estado para a repressão dos insubordinados. Tal produção se utiliza sem limites do forte apelo midiático para a irrupção de subjetividades conduzidas pelo pavor.

Os meios de comunicação de massa, principalmente a televisão, são hoje fundamentais para o exercício do poder de todo o sistema penal, seja através dos novos seriados, seja através da fabricação de indignação moral, seja pela fabricação de estereótipo do criminoso (BATISTA, 2003, p. 33).

A mídia aparece, assim, como um poderoso dispositivo de engendramento de subjetividades ao expor, cotidianamente, situações de caos e desordem, tornando-se disparadora de efeitos de limpeza e ordem, como antídoto do pânico provocado pelo estranho.

Em suma, o clamor e a legitimação da violência estatal são parte de um jogo que deve, por um lado, difundir o medo ao máximo e, por outro, alastrar campanhas de repressão e perseguição aos temíveis, tendo como resultado a adesão subjetiva à barbárie de grandes contingentes populacionais, em defesa da sociedade, ameaçada pelos perigos criados e geridos por essa nova governamentalidade. Segundo Batista (2012, p. 06) "a contenção punitiva, a administração dos medos transformou-se na mais importante forma de governamentalidade”.Para Rauter (2014, p. 13):

Vivemos um momento em que um clamor "aparentemente popular" tem reproduzido, no campo social, a lógica prisional, na qual a possibilidade de suportar o conflito, ou de ter uma postura ética baseada na 'responsabilidade' de todos os atores envolvidos é constantemente recusada, temida, impedida de se manifestar. Sabemos que esse clamor pela solução penal e policial do conflito social atende aos interesses do capitalismo financeiro e é produzido uma rede institucional complexa, da qual a mídia participa como importante ator.

O atravessamento da lógica prisional no campo social, que tem na adesão subjetiva à barbárie seu efeito extremo não apenas visa gerar o bloqueio dos corpos tidos como indesejáveis como impede a possibilidade de invenção de outros modos para lidar com os conflitos em virtude do esvaziamento do coletivo e da produção de subjetividades perpassadas por valores cada vez mais individualistas. 
Os "enclaves fortificados" - condomínios fechados, shopping centers, clubes etc., separados por altos muros e grades, sob a vigilância dos sistemas de segurança - sobre o qual nos falou Caldeira (2000), em termos de privatização do espaço urbano, cumpririam a função de proteger da violência e da mistura com as "pessoas diferenciadas" - os "outros", os não semelhantes - isolando corpos que devem manter-se limpos em seus circuitos protegidos de circulação pela cidade, o que acaba expulsando "de sua visão e de sua experiência o burburinho das cidades e com isso se privam do convívio com as diferenças, tornando-se enrijecidos" (RAUTER, 2014, p. 09). Segundo a autora, quando os processos conflitivos próprios das cidades são simplificados com respostas de penalização ou judicialização, perdese a oportunidade de incorporar o diferente e o novo, e de complexificar-se diante da vida em movimento e expansão.

O esvaziamento do coletivo gera uma ênfase na responsabilidade individual que tende a anular as relações de solidariedade, incitando relações de competição e rivalidade, em que a máxima do "cada um por si" rege a vida solitária, desfiliada socialmente e, por isso mesmo, cada vez mais insegura de cada um. Nesse sentido, a responsabilização individual daqueles historicamente considerados indesejáveis, dá-se numa seleção "natural" não mais resultante do corte dos seres biologicamente inferiores, mas, numa perspectiva neodarwinista, resultante da sua capacidade individual de gerir a vida na atual sociedade de consumo e de risco (BECK, 2010).

Então, temos que a tentativa de se esquivar da complexidade da vida por meio da busca incessante da ordenação do que é considerado caos social, da eliminação do ingovernável, tido como inimigo do Estado; da segregação dos insubordinados; da tentativa de homogeneização da diferença e do estranho; da delimitação e vigilância dos espaços de circulação e moradia; tudo isto diz respeito a modos de viver atravessados pelo medo e por valores predominantemente individualistas: subjetividades capitalísticas, que, medrosas, negam a alteridade e racionalizam os acontecimentos, transformando-os em fatos, o que implica a redução dos seus múltiplos sentidos a versões simplistas e na anestesia da vida diante das vibrações provenientes das experiências coletivas.

\footnotetext{
${ }^{8}$ Expressão usada por uma moradora de Higienópolis, bairro nobre de São Paulo, referindo-se a mendigos, camelôs, etc., quando se discutia, em 2011, a abertura de uma das estações de metrô no bairro e o receio de atrair "pessoas diferenciadas" - leia-se: pessoas pobres, em sua concepção higienista, pessoas perigosas.
} 
Rolnik (1998) afirma que a negação da alteridade encontra na escravatura sua expressão máxima, o que ainda hoje tem efeitos sobre as relações contemporâneas estabelecidas, principalmente, pela elite brasileira que, altamente consumida pelas tecnologias da televisão e pelo medo, evitam experiências com o heterogêneo e perdem a conexão com a vibratilidade do corpo e o vetor ético "para detectar e comprometer-se com aquilo que pede passagem na vida coletiva" (Ibidem, p. 11). Diante dos impasses da vida coletiva, isolam-se e anestesiam seus corpos, desconectando-se da vibração que emerge no contato com outros corpos, e não conseguem elaborar novos sentidos aos eventos complexos da vida, criando como rápida solução a negação da alteridade.

(...) esta marca histórica escravocrata encontra-se inscrita na subjetividade de todo brasileiro. A forte presença dessa marca, acrescida do fato de sermos sujeitos modernos como qualquer outro homem do mundo ocidental do mesmo período histórico, fazem com que estejamos sempre correndo o risco de perder a sintonia fina com o corpo vibrátil, perder a errância do desejo como operador da consistência subjetiva (ROLNIK, 1998, p. 12).

A autora nos fala de modos de subjetivação, ancorada no Movimento Antropofágico ${ }^{9}$, considerando a subjetividade antropofágica como livre de qualquer sistema de referência pela liberdade de misturar-se continuamente e pela plasticidade de criação contínua de novos repertórios diante dos fluxos da vida. Por isso, a prática antropofágica, em sua atualização ética, parte do reconhecimento do outro em sua diferença virtuosa, já que sua força reside na "afirmação irreverente da mistura que não respeita qualquer espécie de hierarquia cultural a priori, já que (...) todos os repertórios são potencialmente equivalentes enquanto fornecedores de recursos para produzir sentido" (Ibidem, p. 06).

A perda de vibratilidade do corpo relaciona-se ao que Rolnik (1998) chama de "baixa antropofagia" referindo-se ao modo de subjetivação daqueles que se consideram parte de uma democracia quando reclamam seus direitos à propriedade privada, à segurança pública para a proteção de seus patrimônios - para complementar a segurança privada que já colocam a seu dispor, ao ir e vir sem a perturbação dos "diferenciados", para o livre consumo do que lhes assedia nas vitrines dos shoppingcenters etc. Refere-se à precaução para evitar as misturas, do qual nos falou Rauter (2014), que, para Rolnik, desalojariam as subjetividades colonizadas por um modo de ser identitário, provocando crises provavelmente apenas curáveis à base de

\footnotetext{
${ }^{9}$ Importante movimento artístico-cultural de tendência modernista no Brasil dos anos 20, que tem Oswald de Andrade como um dos seus criadores. 
psicotrópicos - drogas anestésicas que, na mesma lógica, impedem o contato com o que pede passagem no universo das vibrações sinestésicas, insuportáveis aos corpos modulados. Esta modulação subjetiva relaciona-se ao polo mais reativo da antropofagia, atualizando-se narcisicamente, numa relação em que vale tudo para responder aos interesses do ego, geralmente adequados às tendências do mercado.

Nesta estratégia do desejo, ter um bom desempenho no surf das mudanças implica em ser capaz de consumir o novo e não de criá-lo a partir do que indica a vibratibilidade do corpo. É uma subjetividade desligada do corpo sensível, anestesiada a seus estranhamentos, sem qualquer liberdade de criação de sentido, totalmente destituída de singularidade (ROLNIK, 1998, p. 14).

$\mathrm{Na}$ contramão da atualização narcísica, o polo mais ativo da subjetividade antropofágica, altamente atravessada por um vetor ético, liga-se aos interesses da vida sempre incluindo a alteridade como fundamental para a sua expansão individual e coletiva, rompendo definitivamente com as heranças da escravidão como modelo de relação. Nesse polo de subjetivação, a "alta antropofagia" que a caracteriza:

nos permite suportar melhor a falta de sentido que acontece quando misturas de mundo em nosso corpo nos impõem mudanças de linguagem; improvisar mais facilmente linguagens incomuns para expressar tais mudanças; (...) Isto nos torna mais aptos para alcançar uma consistência subjetiva deslocada do princípio identitário, o que nos permite recusar mais facilmente a figura do atleta da flexibilidade sem medo de ficar inteiramente fora de órbita (ROLNIK, 1998, p. 14).

Retomando o medo como estratégia de governamentalidade neoliberal para a gestão dos corpos, as subjetividades caracterizadas por uma "baixa antropofagia" seriam aquelas facilmente governáveis já que, praticamente, destituídas de pensamento crítico e de repertórios ou capacidade de improviso para lidar com a diferença: são vidas reduzidas a sobrevidas que se arrastam no ritmo que imprime o poder que lhe esmaga a subjetividade criativa. Subjetividades, portanto, incapazes de compor espaços políticos de negociação estabelecidos numa relação de coextensividade com a multidão.

A atividade política enquanto virtude humana é produtora de acordos e contratos provisórios que demandam atividade e potência, e não temor e obediência. Não seria, portanto, a ameaça de punição que levaria à inibição de comportamentos destrutivos ou antissociais, mas o exercício democrático pleno, capaz de incluir todas as forças vivas da sociedade em sua capacidade de resistência e afirmação (RAUTER, 2014, p. 12). 
Por fim, o medo, "móvel amargo e inconfessável dos sujeitos históricos" (CHALOUB apud BATISTA, 2003, p. 37), sentimento atrelado a uma fraqueza humana quase sempre inadmissível ou indizível, é o elemento chave de bloqueio da afectibilidade dos corpos, porque se transforma em motor para a produção de saber e exercício de poder que resultam na constituição de sobrevidas moduladas aos modos capitalísticos de ser. Subjetividades capitalísticas engendradas em jogos de verdade que mascaram o medo como instrumento de manutenção das relações de poder na estruturação das práticas punitivas e arbitrárias de controle social contemporâneas.

\section{DA ESTÉTICA COMO DISPOSITIVO PARA A CONSTRUÇÃO DO COMUM}

Na busca de novos rumos da sensibilidade contemporânea (...), a atividade artística desloca o acento das obras para a produção de acontecimentos, ações, experiências, objetos (...), liberando uma significação básica: a reinvenção da arte é condição para que ela possa intervir na transformação radical do homem e do mundo. Assim fazendo, estaria realizando e ultrapassando as categorias de arte, tornadas categorias de vida, seja pela estetização do cotidiano, seja pela recriação da arte como vida (FABRINIapudLIMA, 2006, p. 325).

Vimos, até aqui, a produção do medo como estratégia de gestão do socius, posição reforçada pela sociedade contemporânea de valores individualistas, que preza pela extrema proteção diante da diferença ameaçadora à sua suposta unidade/coerência no existir, geralmente apoiada em conceitos prévios e distanciados da realidade sobre a qual julga e que serve para justificar seu afastamento. Necessariamente, posição que se faz à distância e fortalece as dimensões fantasiosas do medo. Composição dura que nos permite chegar à equação: quanto mais medo, mais distância (e vice-versa) e mais necessidade de controle sobre o entorno para manter-se separado do estranho que ameaça. Composição que geralmente resulta em relações de poder verticalizadas, de subordinação, imposição, separação, categorização, exclusão e suposto controle. Ilusão de que menos mistura signifique mais pureza; portanto, menos diferença resulte em menos surpresa e supostamente mais previsibilidade, o que garantiria mais controle sobre a vida (sua e do outro) e a diminuição do medo.

De outro lado, apostamos na construção de outros modos de lidarmos com os medos nossos de cada dia: abertura à alteridade, às multiplicidades, à vida em constante devir. Composição molecular e complexa: quanto maior abertura à diferença, maior proximidade e 
desmistificação do estranho, maiores conexões diversas com o mundo, menor o preconceito e maior a defesa da vida em sua singularidade/multiplicidade. Composição que deve resultar em relações de poder mais horizontalizadas, de negociação, de composição, de mistura e de variação, de conflitos e de assertividades, de aproximação sem necessário consenso, de comuns sem padrão ou exclusão. Aposta possível de que quanto maior a abertura, mais mistura, mais laços sociais e constante criação de novos sentidos à vida em movimento e intensidades afetivas, com menor sentimento de ameaça, menor necessidade de controle sobre a vida e, aí sim, menor medo diante do mundo, do novo, do estranho.

Sem receitas nem fórmulas, mas tomando como base a clássica lição de Franco Basaglia: "contra o pessimismo da razão, o otimismo da prática", apostamos na força dos encontros do coletivo para a construção de laços sociais e afetivos mais efetivos, em que o sentimento de pertença e a aproximação com o outro permitam mais relações de confiança para o acesso ao próprio medo até a sua possível transformação ou diluição. Para intervir no plano de organização da realidade, apostamos na conjunção de linguagens em que a comunicação sem palavra, feita em dimensões outras cuja a arte é elemento central, compõe um dispositivo de sensibilização para a captura do olho/corpo vibrátil, afetando-o ao ponto de alterar o regime das fantasias e dos medos.

Segundo Rancière (2009, p. 17), as práticas artísticas são “'maneiras de fazer’ que interferem na distribuição geral das maneiras de fazer e nas suas relações com maneiras de ser e formas de visibilidade". Entendendo a arte como uma prática de trabalho que resulta em alguma produção com uso de técnicas, o autor nos fala da arte como um processo de efetuação material que altera o regime das atividades e ocupações, em geral, na medida em que promove a imanência do pensamento na (ou sua transformação em) matéria do sensível, ou ainda, na medida em que antecipa o princípio que rege qualquer trabalho: a apresentação do reflexo da própria comunidade a si, por meio da experiência sensível que suscita. Se, por um lado, temos a arte em seu processo de criação e seus efeitos de subjetivação sobre quem cria, temos, por outro, os agenciamentos que podem ser feitos da obra com o mundo e seus efeitos de visibilização, enunciação e desterritorialização. Assim como a clínica procura promover processos de vida e de criação, a arte também tem efeito de convocação de novas sensibilidades que exigem movimentos de reterritorialização e, consequentemente, novas subjetividades. 
Captar forças inconscientes que sempre engendram novas configurações sociais - ou as reinventam para que permaneçam praticamente as mesmas; conectar-se aos sintomas de uma sociedade ou uma específica realidade que grita quase muda suas dores e dissabores; anunciar sem palavras o que talvez não fosse tolerável ouvir e que o olho-retina não é capaz de enxergar, são obras da arte. A arte cria "blocos de perceptos e afectos", cria "seres de sensação" a partir da "síntese disjuntiva de um acontecimento e um procedimento, de um tempo originário e de uma busca histórica" (CANGI, 2005, p. 11).

\begin{abstract}
Passar dos grandes acontecimentos e personagens à vida dos anônimos, identificar os sintomas de uma época, sociedade ou civilização nos detalhes ínfimos da vida ordinária, explicar as superfícies pelas camadas subterrâneas e reconstituir mundos a partir de seus vestígios, é um programa literário, antes de ser científico (RANCIÈRE, 2009, p. 49).
\end{abstract}

Encontramos em Rancière (2009) a noção de "partilha do sensível" [partagedusensible] que remete à existência de um comum partilhado e de recortes desse comum que se tornam exclusivos, isto é, além do compartilhamento, refere-se também à divisão, no sentido da distribuição/separação em partes. "A partilha do sensível faz ver quem pode tomar parte no comum em função daquilo que faz, do tempo e do espaço em que essa atividade se exerce” (p. 16). É a partir dessa noção que Cachopo (2013, p. 24) afirma o reconhecimento da imbricação constitutiva entre estética e política: "uma tal partilha do sensível constitui o plano das condições da experiência, da acção e do pensamento". O modo como cada um consegue ocupar, circular e fazer uso dos espaços da cidade, fazendo-se ver e capaz de dizer, definiriam, assim, a qualidade de acesso e construção de um comum e, consequentemente, modos de subjetivação diversos.

De modo algum a construção de um comum refere-se à nostalgia ou retomada da "comunidade perdida" em que o desejo de fusão para estabelecer e manter laços harmoniosos e íntimos entre as pessoas se dariam em correlação com uma comunhão de si mesmo com sua própria essência. Segundo Jean-Luc Nancy (apud MENDES, 2012, p. 131), que, em 1983, problematiza a produção da "sociedade moderna" a partir dessa nostalgia, essa união fusional entre os membros de uma comunidade nunca existiu: essa é uma concepção própria da modernidade. Pelbart (apud MENDES, 2012, p. 132) comenta a problemática extrema do desejo de retorno à comunidade: “O desejo de fusão unitária pressupõe a pureza unitária, e sempre se pode levar mais longe as exclusões sucessivas daqueles que não respondem a essa 
pureza, até desembocar no suicídio coletivo". Não se trata, portanto, de pensar a comunidade como um "ser comum", de modo substancializado, mas

a partir de um "ser-em-comum", que se expõe a todo o momento, como singularidade, a uma alteridade que lhe informa. A comunidade não é mais definida por uma fusão ou comunhão, mas por uma abertura comum. É o conceito de partage que explica essa "abertura" como disposição própria da singularidade (MENDES, 2012, p. 134).

A partir de Negri (2005), a constituição do comum pode ser entendida como construção de espaços comuns reais entre singularidades, que articuladas e sempre pautadasno reconhecimento do outro e na relação com o outro, é capaz de constituir uma realidade, também chamada de multidão, em que há espaço para a decisão, para o desejo e para a capacidade contínua de transformação das singularidades. É, portanto, o espaço da diferença e dos conflitos, os quais devem ser mantidos acesos se quisermos resistir aos processos de homogeneização, totalização e individualização, próprios da biopolítica. Segundo Negri (2005, p. 06) "isto é a constituição do comum. É esta participação, esta capacidade de assumir pelas próprias mãos as condições biopolíticas da própria existência, do próprio modo de trabalhar". Assim, a produção de "um comum" é um "estar com" capaz de gestar "novas 'modalidades de insubmissão, de rede, de contágio, de inteligência coletiva', onde se inscrevem as afetações, a produção de laços e a inventividade" (PELBART apud VASCONCELOS;MORSCHEL, 2009, p. 734).

No entanto, a construção de um comum com novas modalidades de articulação dos corpos sensíveis e não submissos, em direção a práticas éticas e inventivas só se torna possível se atravessada por novas afetações, o que exige a construção de espaços de visibilidade que pode ser feita por meio da arte. Para Rancière (2009, p. 16), as formas de visibilidade das práticas das artes têm efeitos na construção de um comum e dizem respeito às práticas estéticas: recortes do visível e do invisível que definem "o que está em jogo na política como forma de experiência”. São as ações micropolíticas que atuam no plano da criação da obra, do sujeito, do encontro que mobiliza e desloca "as distinções, hierarquias e tensões existentes entre visível e invisível, audível e inaudível, imaginável e inimaginável" (CHACOPO, 2013, p. 25).Segundo Cangi (2005, p. 16), 
composição) e a visibilidade singular formal (variedades nos procedimentos de criação). Esta passagem do invisível ao visível é o que chama de 'fazer o movimento'.

Como nos diz Fonseca, Kirst e Amador (2011, p. 115), “o espaço de visibilidade não existe como cena", não está lá pronto para ser visto. Ele precisa ser habitado para ser possível "fazer o movimento" do qual nos fala Deleuze. Muitas vezes, são espaços prenhe de práticas corriqueiras e tão naturalizadas que não se enxerga a força de coerção que os caracteriza e que se expressa sobre os corpos que tem como alvo. Como dizem as autoras:

\begin{abstract}
Nossos percursos conduzem-nos a considerar que existem lugares que são inexplicáveis e que resistem à descrição. O intolerável que os habita exerce a função de atrator de nosso olhar e somos fisgadas pelas forças que atravessam aquelas paisagens humanas, em que homens e mulheres deslocam-se, como que "separados do mundo, cada um com a sua noite, cada um com sua morte" (CELAN apud FONSECA; KIRST; AMADOR, 2011, p. 115).
\end{abstract}

A produção imagética, seja na fotografia, na xilogravura ou no cinema, recria o mundo em forma de ficção e, este, redesenhado, retorna ao sujeito como um acontecimento capaz de romper evidências e fazer emergir singularidades. A potência de recriação do mundo por meio da arte retira o corpo do campo reativo e possibilita, a partir de linhas de fuga inventivas, uma posição de resistência, a qual deve corresponder "ao exercício da manutenção da sensibilidade e da abertura às feridas sutis" (Ibidem, p. 120).

Nos rastros das autoras, apostamos na política feita também a partir da imagem a serviço da vida, retomando sua afectibilidade, sua capacidade de ser afetada no e com o corpo vibrátil, como modo de resistir ao sobrevivencialismo, do qual nos fala Pelbart (2009), como modo de abrir espaços de expressão da potência da vida contra as forças sobre a vida, da biopotência contra os efeitos esmagadores da biopolítica. "Assim, é a consciência que é tomada pelas vibrações do corpo, em lugar da tomada de consciência pelo exercício das racionalidades, que se afirma como caminho de mudança social” (FONSECA; KIRST; AMADOR, 2011, p. 123).

Quando falamos nos efeitos da clínica como promotora de processos de vida e de criação, assim como a arte, queremos dizer que não podemos falar em clínica apartada da política, já que não é possível pensar a configuração do campo social apartado do desejo e vice-versa. Falamos, portanto, da clínica como prática estética que tem efeitos de subjetivação: "artísticos podem ser momentos clínicos de intensidade ímpar, que não podem 
ser repetidos, mas que têm a potência de provocar mutações subjetivas, ampliar a capacidade de alguém de ser afetado e potencializar a vida" (LIMA, 2006, p. 325).

Neste sentido, a arte é dispositivo de subjetivação produtora de espaços de criação de vida que, necessariamente, questionando a suposta ordem do mundo e retomando sua complexidade, promove diferenciações e variações para fazer frente aos processos homogeneizantes e mortificantes da serialização biopolítica. Guattari (2012, p. 66), entendendo o mundo como máquina produtora de heterogênese, isto é, "abertura para processos irreversíveis de diferenciação necessários e singularizantes”, opõe-se à visão de homogênese do homem clássico e sua ideia de ordem e considera o caos e a complexidade como elementos que o colocam em constante devir, portanto, uma obra de arte permanente.

Ao contrário de destruição e morte, a desordem e as transformações provocam diferenciações em função da complexidade dos acontecimentos. Segundo o autor, o caos é essencialmente dinâmico e nele habita uma raridade informacional que, ao nível dos afetos e perceptos, mobiliza potencialidades criativas e constitui composições hipercomplexas, capazes de deslocamentos e desconstruções importantes para mudanças no campo social. Tal criação e composição dizem respeito a um paradigma estético que tem expropriado os antigos paradigmas cientificistas na medida em que máquinas de desejo e de criação remanejam e alargam nossas fronteiras subjetivas, ocupando lugar eminente no interior dos agenciamentos de subjetivação.

É a partir de um novo paradigma estético, com implicações ético-políticas, que concordamos serem possíveis efeitos de derivação dos modos de ver e falar delimitados por um determinado dispositivo e seus efeitos de subjetivação, os quais podem romper com esquemas pré-estabelecidos, considerando a alteridade em suas modalidades extremas. Para Guattari (2012, p. 105):

Todo descentramento estético dos pontos de vista, toda multiplicação polifônica dos componentes de expressão, passam pelo pré-requisito de uma desconstrução das estruturas e dos códigos em vigor e por um banho de caósmico nas matérias de sensação, a partir das quais torna-se-á possível uma recomposição, uma recriação, um enriquecimento do mundo [...], uma proliferação não apenas das modalidades de ser.

Nesse sentido, ele fala da necessidade de se constituir novos complexos de subjetivação: “indivíduo-grupo-máquina-trocas múltiplas, que oferecem à pessoa 
possibilidades diversificadas de recompor uma corporeidade existencial, de sair dos seus impasses repetitivos e, de alguma forma, de se ressingularizar" (Ibidem, p. 17).

É bom que se diga que o paradigma estético não se refere apenas a processos criativos relacionados à arte e muito menos se restringe a artistas profissionalmente assim denominados. A capacidade de invenção extrapola as práticas artísticas e pode engendrar composições de afetos e perceptos a partir de toda uma criatividade subjetiva referente a modos de ser e modos de atuar no mundo relacionados à liberação de povos e gerações oprimidas, minorias e corpos tidos antes como abjetos. Mas é claro que mesmo que a arte não detenha o monopólio da criação, ela pode levar aos extremos a criação de realidades inéditas, nunca antes vista, vivida ou pensada.

É nas trincheiras da arte que se encontram os núcleos de resistência dos mais consequentes ao rolo compressor da subjetividade capitalística, a da unidimensionalidade, do equivaler generalizado, da segregação, da surdez para a verdadeira alteridade (GUATTARI, 2012, p.121).

\section{DISPOSITIVOS ESTÉTICOS DE DESINSTITUCIONALIZAÇÃO DO "LOUCO} INFRATOR"

Acreditando na força disruptiva da arte e na sua consequente atuação como "microvetor ético dessegregadores de alteridades" (CECCIM, 2007), criamos diversos dispositivos estéticos, dentre os quais:oficinas de arte oferecidas a internos do Hospital de Custódia e Tratamento Psiquiátrico/HCTP do Pará,uma exposição itinerante das obras resultantes, rodas de conversa com trabalhadoresda saúde mental e a produção de um filmedocumentário, exibido e debatido em diversos serviços de saúde, universidades e outros espaços públicos, na Região Metropolitana de Belém, alcançando mais de 1200 pessoas.

As oficinas de xilogravura e fotografia artesanal geraram imagens sobre o que ninguém que ver criadas por aqueles historicamente considerados incapazes e sub-humanos; a exposição de suas obras em diversos espaços que executam direta ou indiretamente a medida de segurança no Estado do Pará - dentre eles: TJPA, Ministério Público, Secretaria Estadual de Saúde do Pará eCentros de Atenção Psicossocial, onde promovemosrodas de conversa- e a exibição, seguida de debate, do filme-documentário, sobre internos e egressos do mesmo HCTP,foram meios utilizados para provocar perturbações, diferenciações nos enquadramentos que sustenta o dispositivo medida de segurança, emaranhando as visibilidades, enunciações e relações de força que a constituem e buscando questionar e torcer 
seus sentidos mais naturalizados, suas formas mais duras, em direção à atualização das suas virtualidades. As rodas deconversa nos serviços de saúde mental permitiram que se analisasse na perspectiva dos profissionais os regimes de afetabilidade que impediam que se desenhassem projetos e ações de cuidado na direção da desinternação e da inclusão.

Nos rastros de Guattari (2012), tais meios são micro-dispositivos ético-estéticopolíticos, considerando:

a ética como o reconhecimento da alteridade, referida não ao parâmetro da tolerância ou da intolerância, mas ao desafio da convivência que não implica em consenso redutor ao mesmo, ao um, mas a acordos possíveis e temporários; a estética traz a dimensão da criação, já que não há conhecimentos universais para serem aplicados, mas uma diversidade de injunções que desafiam o pensamento, a ação e a sensibilidade para a produção de novos processos de existência; a política afirma a responsabilização frente aos efeitos produzidos nas práticas e os compromissos e riscos implicados com as tensões e as posições assumidas (ROCHA, 2006, p. 171).

A arte, em diversas linguagens - fotografia, xilogravura, cinema, performance, poesia -, foi trabalhada considerando o regime estético das artes, o qual se opõe ao sistema representacionista; não mais separa pensamento ativo de sensibilidade passiva; não submete o dado intuitivo a qualquer determinação conceitual; e, por isso, não aparta quem supostamente pensa e decide dos que aparentemente são destinados aos trabalhos materiais. A partir da arte buscamos trabalhar coletivamente na "transformação da matéria sensível em apresentação a si da comunidade [...]. [Trabalhando] a arte como transformação do pensamento em experiência sensível da comunidade" (RANCIÈRE, 2009, p. 67).

\section{CONSIDERAÇÕES FINAIS}

Do interior desse dispositivo de exceção, o manicômio judiciário, fomos arremessadas do insuportável para construção coletiva de dispositivos de desinstitucionalização: contradispositivos com força disruptiva dessa máquina de morte. Sem dúvida, este espaço mostra-se como parte do contexto de sufocamento que a humanidade se encontra contemporaneamente, sobre o qual se refere Perlbart (2006), o qual deveria nos impelir a mudar a direção, abrir espaço para inventar outros jogos, outros modos de vida e relação. Com isso, buscamos captar o intolerável para desconstruir sua naturalidade e abrir passagens à vida em sua potência, "manancial de sentidos inesgotáveis" e não suprimíveis nem pela mais totalitária das instituições totais. 
Nesse sentido, a pesquisa pôs em ação dispositivos estéticos de desinstitucionalização que funcionaram conectando indivíduos, grupos, instituições e efetuando múltiplas trocas e recomposição das corporeidades e afetações. As oficinas, a exposição itinerante, as rodas de conversa e o filme-documentário buscaram tornar visível o invisível, promovendo o acessoe, em alguma medida, o cuidado dos medos,que se encontram na base das práticas de segregação, com o intuito deembaralhar os códigos das racionalidades que constituem a medida de segurança para o desmanche das significações padronizadas.

Fizemos referência à arte como experiência-limite produzida no interior de um manicômio judiciário: lugar que não se quer ver, que produz vidas invisíveis e é movido por forças que permanecem ainda hoje subterrâneas e, por isso, pouco ou nada visibilizadas. Experiências-limite que jogam luz sobre o que a humanidade foi capaz de criar para lidar com os seus indesejáveis e que a cultura rejeita enxergar, mas que abrem caminho para que se dê "visibilidade ao mais impalpável e legitimidade àquilo que o senso comum social despreza, teme ou abomina, [invertendo-se, assim,]o jogo das exclusões sociais e sua crueldade" (PELBART apud LIMA, 2006, p. 326). Criar dispositivos estéticos nos possibilitou dar visibilidade às forças coercitivas que envolvem e assujeitam os corpos produzidos como indesejáveis nos insuportáveis espaços de tortura e morte que são os HCTP.

Em tempos sombrios, cujas arbitrariedades e violências tomam cada vez mais corpo para a gestão dos corpos indesejáveis e para incutir medo aos que seguem preferindo a omissão diante de tamanhas violações, o paradigma ético-estético-político nos desafia para a criação de práticas e saberes que rompam com tais instrumentos de governamentalidade e, ao mesmo tempo, promovam dispositivos capazes de criar outras configurações sociais e políticas em direção à constituição do comum.É na mistura, nas aproximações, encontros e trocas no coletivo, com todas as divergências e diferenças que o constitui, que apostamos na criação de novas modalidades de insubmissão, de inteligência coletiva e afetações diversas e, como consequência, no engendramento de novas sensibilidades e subjetividades que reconheçam o outro em sua singularidade e subvertam os mecanismos de exclusão e segregação incrustados historicamente entre nós e atualizados permanentemente. 


\section{REFERÊNCIAS}

BATISTA. V. M. Adesão subjetiva à barbárie. In: BATISTA, V. M. (Org.). Lö̈cWacquant e a questão penal no capitalismo neoliberal. Vol. 1. Rio de Janeiro: Revan, 2012.

BATISTA, V. M. O medo na cidade do Rio de Janeiro: dois tempos de uma história. Rio de Janeiro: Revan, 2003

BECK, U. Sociedade global de risco: rumo a uma outra modernidade. Trad. Sebastião Nascimento. Editora 34: São Paulo, 2010.

BRASIL. Lei n. 7.210/1984.Institui a Lei de Execução Penal. Brasília, 1984.

CACHOPO, João Pedro. Momentos estéticos:Rancière e a Política da Arte. AISTHE, Vol. VII, n. 11, 2013.

CALDEIRA, T. P. R. Direitos humanos ou "privilégios de bandidos"? Desventuras da democratização brasileira. In: Novos Estudos, n 30, p. 162-174, jul. 1991.

CALDEIRA, T. P. R. Cidade de Muros: Crime, Segregação e Cidadania em São Paulo. São Paulo: Editora 34/Edusp, 2000.

CALDEIRA, T. P. R. Violência, direitos e cidadania: relações paradoxais. Revista Ciência e Cultura. vol. 54, n. 1, São Paulo, jun./set. 2002. Disponível em: http://cienciaecultura.bvs.br/pdf/cic/v54n1/v54n1a21.pdf. Acesso em: 07 maio 2015.

CANGI, A. Gilles Deleuze: o ato da criação. In: MACIEL JÚNIOR, A.; KUPERMANN, D.; TEDESCO (Orgs.). Polifonias: clínica, política e criação. Contra Capa Livraria: Mestrado em Psicologia da Universidade Federal Fluminense, 2005.

CECCIM, R. B. Reforma geral da subjetividade: por uma educação rizomática da saúde mental Prefácio. In: FONSECA, T. M. G.; ENGELMAN, S. e PERRONE, C. M. Rizomas da reforma psiquiátrica: a difícil reconciliação. Porto Alegre: Sulina, 2007.

COIMBRA, C. M. B. Discursos sobre segurança pública e produção de subjetividades: a violência urbana e alguns de seus efeitos. Trabalho de Pós-Doutorado, NEV/USP, 1998.

COIMBRA, C. M. B. Psicologia, direitos humanos e neoliberalismo. In: Revista Psicologia Política, 1(1), jan./jun., p. 139-148, 2001.

DELEUZE, Gilles e GUATTARI, Félix. Mil platôs: capitalismo e esquizofrenia - Volume 3. São Paulo, Ed. 34, 1996.FONSECA, T. M. G.; KIRST, P. G.; AMADOR, F. S. Corpo, arte e clínica: variações na pesquisa como resistência e diferenciação. In: Revista Vivência, n. 36, p. 113-125. 2011. FOUCAULT, M. O Sujeito e o Poder. In: DREYFUS, H.; RABINOW, P. Michel Foucault, uma trajetória filosófica: para além do estruturalismo e da hermenêutica. Tradução de Vera Porto Carrero. Rio de Janeiro: Forense Universitária, 1995. 
FOUCAULT, M. Em defesa da sociedade. Curso no Collège de France (1975-1976). São Paulo: Martins Fontes, 2005.

FOUCAULT, Michel. Vigiar e Punir: História da Violência nas Prisões. 9. ed. Petrópolis: Vozes, 2010.

GOFFMAN, E. Manicômios, prisões e conventos. 7 ed. São Paulo: Perspectiva, 2001

GUATTARI, F. Caosmose: um novo paradigma estético. Trad. Ana Lúcia de Oliveira e Lúcia Cláudia Leão. $2^{\text {a }}$ ed. São Paulo: Editora 34, 2012.

KOLKER, T. A Tortura e o Processo de Democratização Brasileiro. In: RAUTER, C; PASSOS, E., BENEVIDES, R. (Orgs.). Clínica e política: subjetividade e violação dos direitos humanos. Equipe Clínico-Grupal, Grupo Tortura Nunca Mais - RJ. Rio de Janeiro: Instituto Franco Basaglia, TeCora, 2002.

LIMA, E. M. F. de A. Por uma arte menor: ressonâncias entre arte, clínica e loucura na contemporaneidade. In: Interface - Comunicação, Saúde, Educação, v.10, n.20, p. 317-29, jul./dez. 2006.

MATSUMOTO, A. E. Práxis social e emancipação: perspectivas e contradições no Estado Democrático de Direito Penal. Tese (Doutorado em Psicologia) - Programa de Estudos PósGraduados em Psicologia Social, Pontifícia Universidade Católica, São Paulo, 2013. $200 f$

MENDES, A. F. Para além da "Tragédia do Comum": conflito e produção de subjetividade no capitalismo contemporâneo. Tese (Doutorado em direito), Universidade do Estado do Rio de Janeiro, Rio de Janeiro, 2012. 190f.

NEGRI, A. Conferência Inaugural do II Seminário Internacional Capitalismo Cognitivo: Economia do Conhecimento e a Constituição do Comum. 24 e 25 de outubro de 2005, Rio de Janeiro. Disponível em:

$<$ https://loomio-

attachments.s3.amazonaws.com/uploads/9d03ca732f05c41d4795b6d2b538670b/a-constituicao-docomum-traducao.doc.> Acesso em: 08 jul. 2014.

PELBART, P. P. Nuda vida, vida besta, una vida. In: Euphorion, v. 1, p. 34-42. 2009.

RANCIÈRE, J. A partilha do sensível:estética e política. $2^{\mathrm{a}}$ ed. São Paulo: EXO Experimental; Editora 34, 2009.

RAUTER, C. Responsabilidades, Adolescência e Violência Contemporânea: a positividade do conflito em Spinoza, Maquiavel e Winnicott. In: Revista Brasileira de Ciências Criminais, n. 109, p. 47-59, jul./ago. 2014.

ROCHA, M. L. Psicologia e as práticas institucionais: a pesquisa intervenção em movimento. In: PSICO, v. 37, n. 2, p. 169-174, mai./ago. 2006. Disponível em: $<$ http://revistaseletronicas.pucrs.br/ojs/index.php/revistapsico/article/view/1431/1124>. Acesso em: 15 maio 2015. 
ROLNIK, S. Subjetividade Antropofágica/AnthropophagicSubjectivity. In: HERKENHOFF, P.; PEDROSA, A. (Edit.). Arte Contemporânea Brasileira: Um e/entre Outro/s, XXIV Bienal Internacional de São Paulo. São Paulo: Fundação Bienal de São Paulo, 1998. p. 128- 147. Disponível em: Acesso em: 02 jun. 2015.

ROSE, N. Como se deve fazer a história do eu? In: Educação e Realidade, 26 (1), p. 33-57. 2001.

SILVA, A. A. Das vidas que não (se) contam: dispositivos de desinstitucionalização da medida de segurança no Pará. 2015. Tese (Doutorado em Psicologia Social).Programa de Estudos Pós-Graduados em Psicologia Social, Pontifícia Universidade Católica, São Paulo, 2015. 345f.

VASCONCELOS, M. de F. F.; MORSCHEL, A. O apoio institucional e a produção de redes: do desassossego dos mapas vigentes na Saúde Coletiva. In: Interface - Comunicação, Saúde, Educação. v.13, supl.1, p. 729-738. 2009.

VERDÉLIO, A. Com 726 mil presos, Brasil tem terceira maior população carcerária do mundo.EBC Agência Brasil.Disponível em: <http://agenciabrasil.ebc.com.br/geral/noticia/2017-12/populacaocarceraria-do-brasil-sobe-de-622202-para-726712-pessoas >. Acesso em: 15 jan. 2018.

WACQUANT, L. As prisões da miséria. Rio de Janeiro: Jorge Zahar, 2001.

WACQUANT, L. Punir os pobres: a nova gestão da miséria nos Estados Unidos. Rio de Janeiro: Revan, 2007.

ZAFFARONI, E. R. O inimigo no direito penal. Tradução de Sérgio Lamarão. 2. Ed. Rio de Janeiro: Revan, 2007. 